\title{
How education orientation affects attitudes toward wind energy and wind farms: implications for the planning process
}

Vendula Betakova* ${ }^{*}$, Jiri Vojar and Petr Sklenicka

\begin{abstract}
Background: Three groups of stakeholders are mainly involved in the planning, assessment, and approval processes for wind parks: the planners, the public, and the responsible public authorities. These groups have varying aims, and there are various ways of looking at proposals to set up a wind park. In particular, the viewpoints of planners and government officers are likely to differ. Planners are likely to focus on technical aspects of a wind farm project, while the public authorities are likely to be oriented toward environmental considerations.
\end{abstract}

Methods: The effect of respondents' characteristics on landscape perception was analysed using generalized linear mixed models (GLMM). Set of various landscape images with and without wind turbines (WTs) was evaluated on a 15points scale. The evaluation was accomplished with additional questions about general attitude toward wind energy, willingness to live close to WTs and presence of WTs near respondents' homes.

Results: Using a questionnaire presented to university students in technical study programmes and to students in environmental study programmes, it has been determined that educational orientation substantially influences people's perception of wind turbines (WTs). Respondents pursuing technical studies evaluated landscapes with WTs more positively than did students in environmentally oriented study programmes. In addition, the responses of students in environmental study programmes were influenced by their general attitude toward wind energy, unlike the responses of the technically oriented students. We also examined the influence of respondents' other characteristics on their perceptions of WTs in the landscape, including their general attitude toward wind energy and their willingness to live near WTs, toward the presence of WTs in the vicinity of their place of residence, and interactions among these factors.

Conclusions: Our study indicates the importance of education in planning wind parks. Sanctioning bodies should be able to evaluate each proposed project adequately and impartially, and to assess the potential level of impact of the proposal on the landscape and on landscape values, including aesthetic values, and on the population, and also other impacts caused by the construction and the functioning of WTs. This kind of professional knowledge is also very important for planners. One way to raise students' awareness and their professional knowledge could be through interdisciplinary coursework on this topic.

Keywords: Wind energy, Educational orientation, Visual impact, Distance, Decision-making process

\footnotetext{
* Correspondence: betakova@fzp.czu.cz

Faculty of Environmental Sciences, Czech University of Life Sciences Prague,

Kamycka 129, 16521 Prague 6, Czech Republic
} 


\section{Background}

In the past two decades, wind energy has become a primary renewable energy source. This is demonstrated not only by the prominent construction of a large number of wind parks, but also by the development of modern wind turbines (WTs). WTs now exceed $100 \mathrm{~m}$ in height and achieve outputs of 23 MW [1]. While renewable sources are generally perceived positively and sympathetically, specific wind farm projects are very frequently considered undesirable by the public. Projects are often being rejected, and construction may be halted [2-6].

A number of studies on the acceptability of WTs have been published, dealing not only with respondent characteristics but also with the types of landscape where WTs are located. Analyses of respondents' perception of WTs have focused on the impact of characteristics such as age, gender, education level, and distance on the home or place of frequent sojourn from WTs, as well as the so-called not-in-my-back-yard (NIMBY) effect. Strong opponents of WTs appear to be older and more highly educated $[7,8]$, and differences in attitudes between genders are often minimal [7]. No NIMBY effect has been demonstrated as a motivation for a negative response to the construction of WTs [9-11]. The results of certain studies have demonstrated that people living in the vicinity of WTs paradoxically perceive them more positively than do people living further away from them $[6,12]$. However, it is not entirely clear to what extent people can become accustomed to wind parks and what causes people who frequently spend time in the vicinity of WTs to have a positive perception of them. There are conflicting results on the extent to which the perception of WTs is influenced by living in their vicinity. A study by Eltham et al. [13] demonstrated a more positive evaluation by respondents in 2006 that there called opinions of 1991 . However, a study by Groth and Vogt [14] reports the opposite findings. A negative perception of WTs can last for several years after the construction is completed. The main causes are higher prices for electricity, and noise from the operation of turbines. Similar results can be found in a study from Texas, where the people living closest to WTs were the least supportive of wind parks [15].

The NIMBY effect has become an implicit phenomenon when planning most large investment proposals, including wind parks. Present-day research sometimes indicates that respondents are concerned about being labelled as NIMBYs [16]. The literature has therefore established more acceptable explanations for opposition to the construction of WTs, namely place attachment [17-19], sense of identity [16], and confidence in the structure itself and in its benefits [20]. Place attachment is very important in forming a positive environment for local inhabitants [21, 22].
Landscape is perceived not merely as scenery, but also as a dwelling space [23].

Research has also demonstrated that financial participation and profit for municipalities is a relevant factor, and that it may increase the acceptability of planned wind farms in the vicinity [24]. This goes together with fair communication and with participation in the planning process. Huebner [24] suggests visits to wind parks, moderated workshops, and the use of local expert knowledge to discuss suitable areas and to mitigate the visual impact on the landscape.

Other studies have confirmed that WTs are perceived very negatively in aesthetically valuable and natural landscapes [25-27], as opposed to landscapes already more markedly influenced by human activities. Nevertheless, planning organizations and development companies continue to attempt to construct WTs in these valuable landscapes, predominantly in mountain and coastal areas with a very marked morphology and rich natural cover. These are of course areas with a high wind potential. This issue was examined in a study carried out in the Netherlands [28], which compared the attitudes of environmentalists and the government architect when the proposed large wind energy park in the Wadden Sea area, a protected area in the Netherlands, was halted following a lengthy debate. The influence of knowledge from a certain professional orientation on the perception of WTs is therefore evident. To date, however, there has been no study examining the possible influence of the type of university education and subsequent professional development on the perception of WTs as new technological structures in the landscape. This situation is analogous to the perception of post-mining areas, where the way in which respondents with a professional focus on landscape ecology perceive post-mining landscapes differs markedly from the perceptions of respondents of other orientations [29]. Another study testing the opinion of university students on the placement waste dumps demonstrates that the differing perceptions of respondents are influenced by their level of environmental knowledge [30]. In another study, the level of professional knowledge about natural fires contributed markedly to an increase in support among local inhabitants when planning strategies after naturally occurring fires [31].

Is education important for wind park planners? What education should members of a sanctioning body have in order to make an objective assessment of the suitability of WTs and not to be biased by their educational backgrounds? To answer these questions, we analysed the perception of several different landscape scenes without WTs and with various numbers of WTs at various distances from the observer in a sample of university students in environmental study programmes and in 
technical study programmes. A further objective was to determine the influence on the respondents of their general attitudes toward wind energy, the proximity of their homes to WTs, and their willingness to live near WTs, and also whether people can to a certain degree become acclimatized to WTs.

\section{Methods}

\section{Study design}

In order to analyse perceptions of the aesthetic value of landscapes with and without WTs, WTs were visualized in three different types of landscapes, in different numbers, and at varying distances from the observer. Students of two universities with different educational orientations were selected as respondents: students of the Faculty of Environmental Sciences at the Czech University of Life Sciences in Prague and students of the Faculty of Civil Engineering and at the Faculty of Architecture at the Czech Technical University in Prague. The students were selected with a view to comparing the perception of WTs in the landscape by students of engineering and students of environmental studies. Students form a relatively homogeneous group, differentiated mainly by their field of study. This is advantageous from the perspective of filtering out the potential influences of level of education and of age [30]. Three different landscapes with various levels of human influence, located in the territory of the Czech Republic, were selected for evaluation. One objective of this study was to measure the effect of various levels of human influence on the landscape. The inclusion of multiple landscape types reduced the effect of any relationship that a respondent might have to a specific area (i.e. a place attachment; $[18,19])$. Landscape A depicts the Bohemian Central Uplands, a protected landscape area located in north Bohemia and characterized by a distinctive morphology and diverse cover. Natural features are predominant, forming an aesthetically valuable scene with a harmonious scale. Landscape B is from the Želiv area of the Bohemian-Moravian Highlands, which is morphologically not very distinctive. There is a higher level of visible human influence, but it is in balance with the natural and landscape features. Landscape $C$ is located in central Bohemia, near Neratovice. It represents a landscape type that is markedly influenced by human activities. The natural features are suppressed, and the landscape does not have a marked morphology or cover.

For the evaluation, a set of 39 images was created. In each landscape type, various numbers of WTs were visualized $(1,5,10,15,20$, and 25) at two different distances (1.5 and $5 \mathrm{~km}$ ). Vestas 90-type WTs (height $105 \mathrm{~m}$, rotor diameter $90 \mathrm{~m}$ ) were selected for the visualization. A combination of three landscape types with visualizations of six varying numbers of WTs at two distances formed a set of 36 images. Images of each landscape without WTs also added, making a total of 39 images for evaluation. Respondents were asked to evaluate the images. The images were presented in random order, so as to prevent any influence on the rating, for example, due to an increasing number of WTs within the landscape scene. Simple questionnaires were used for the rating, with each respondent allocating a score ranging from +7 to -7 to each numbered picture ( +7 being the most positive rating, -7 the most negative, and 0 as neutral). Before the ratings were made, the pictures were projected for the respondents without the presence of WTs and with a visualization of 1 WT and 25 WTs for each landscape type. This enabled the respondents to acquire a context for the ranking scale.

After they had evaluated the pictures, the respondents were asked to provide answers to three questions: (1) What is your general attitude toward wind energy? Possible answers: $\mathrm{P}$-positive, $\mathrm{O}-$ neutral, $\mathrm{N}$-negative. (2) Would you be willing to live near WTs? Possible answers: Yes, willing (W); No, not willing (NW); I am indifferent or have no opinion (X). (3) Do you live near a wind power plant (i.e. within $10 \mathrm{~km}$ )? Possible answers: Yes, No. The distance of $10 \mathrm{~km}$ was set on the basis of previous experience as a level at which a WT still has an impact on the aesthetic evaluation of a landscape [25, 32]. In order to prevent any preliminary influence on the respondents' ratings, these questions were presented only after they had rated the set of images. The rating was performed in large lecture rooms using screen projections. The same period of time (10 s) was allotted for rating each image.

\section{Data processing}

The effect of respondents' characteristics (see Table 1) on landscape perception was analysed using generalized linear mixed models (GLMM). Within GLMM, we used the glmer function, which is a part of the

Table 1 Effects of respondents' characteristics and their interactions (last four rows) on their perception of landscapes with wind turbines (WTs)

\begin{tabular}{|c|c|c|c|c|}
\hline Variable & Abbreviation & Df & Chi & $P$ \\
\hline Type of education & Education & 1 & 673.94 & $<10^{-6}$ \\
\hline Willingness to live near WTs & Willingness & 2 & 267.86 & $<10^{-6}$ \\
\hline $\begin{array}{l}\text { Presence of WTs within } 10 \mathrm{~km} \\
\text { of the respondent's home }\end{array}$ & Presence & 1 & 55.46 & $<10^{-6}$ \\
\hline $\begin{array}{l}\text { General attitude toward wind } \\
\text { energy }\end{array}$ & Attitude & 2 & 17.86 & $<10^{-4}$ \\
\hline Education: attitude & & 2 & 187.26 & $<10^{-6}$ \\
\hline Presence of WTs: attitude & & 2 & 60.31 & $<10^{-6}$ \\
\hline Willingness: attitude & & 4 & 11.98 & 0.02 \\
\hline Willingness: education & & 2 & 4.59 & 0.10 \\
\hline
\end{tabular}

Df degrees of freedom, Chi value of test statistic, $P$ obtained probability (levels lower than 0.05 indicate a significant result (i.e. effect of a variable on landscape perception) 
lme4 package of $\mathrm{R}$ statistical freeware, version 3.0.2 [33]. Each of the 39 landscape photographs with a specific combination of the number of WTs $(1,5,10$, 15,20 , and 25) and the distance of the observer from the WTs $(1.5$ and $5 \mathrm{~km})$ was evaluated by 285 respondents. Landscape perception (i.e. respondents' ratings of the photos; $n_{\text {resp. }}=285 \times 39$ ratings $=11,115$ rows) represented in our model a semiquantitative response variable on a 15 -point assessment scale (from -7 to +7 including zero). This variable was converted into a variable with a binomial distribution comprising two vectors-the real landscape assessment value of each respondent and the supplement to the maximum evaluation value. For example, if a certain landscape assessment awarded by any respondent was +5 , the supplement to the maximum evaluation $(+7)$ was 2 . The value of +5 represents here the degree of success (i.e. how much the particular respondent liked the landscape), and supplement 2 represents the degree of failure (the higher the value, the more negative the assessment is). Following the rules for modelling with binomial errors (according to [34]), we used the cbind function, and we bound together the two above-mentioned vectors of the response variable into a single object $y$. This object $y$ was then used in the GLMM analyses as the response variable with a binomial distribution.

The respondents' attitude toward wind energy (attitude: positive $\times$ neutral $\times$ negative), the presence of WTs within $10 \mathrm{~km}$ of the respondent's home (yes $x$ no), the response to the question "Would you be willing to live near WTs?" (willingness: willing $\times$ not willing $\times$ no opinion), the type of study programme that the respondent had chosen (technical $\times$ environmental), and the interactions between these variables comprised the explanatory variables in our model. As was mentioned above, each photo was evaluated by 285 respondents. To avoid pseudoreplications, identification of the photo was included as a random factor in the model. GLMMs were used for this. Using GLMM and photo identification as a random factor, we also solved the potential problem of differing evaluations of scenes according to the different numbers and distances of WTs.

The significance of each explanatory variable in both models was analysed using deletion tests and a backward selection procedure. The final model, consisting of only significant variables, was finally checked using standard statistical diagnostics [34].

\section{Results}

Type of education-orientation of the study programme A significant difference was detected in the evaluations of landscapes with WTs according to students' school

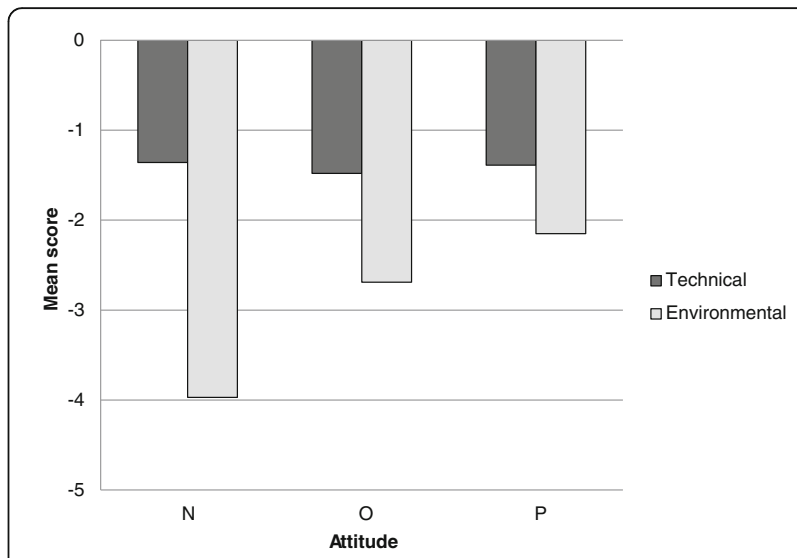

Fig. 1 Mean score of landscape evaluations according to type of education (environmental versus technical) and according to the respondent's general attitude toward wind energy ( $N$ negative, $O$ neutral, $P$ positive)

affiliation. This is the most significant factor among all those monitored (Table 1). Students with a technical orientation awarded markedly higher ratings to landscapes with WTs (mean evaluation \pm SD $-1.46 \pm 3.11$ ) than did students with an environmental orientation $(-2.77 \pm 3.77)$. An interesting relationship was found in the interaction between the factors type of education (education) and general attitude toward wind energy (attitude). While technical students' ratings were practically unaffected by their attitudes toward wind energy, the ratings awarded by environmental students were strongly influenced by their attitudes toward wind energy-the ratings increased with the respondent's more positive attitude toward wind energy (Fig. 1). Further interactions between the education variable and other factors were inconclusive.

\section{Willingness to live near WTs}

Willingness to live near WTs had a strongly significant influence on the ratings (Table 1). Respondents who were unwilling to live near WTs (NW) awarded the lowest ratings (mean $\pm \mathrm{SD}-2.62 \pm 3.35$ ), while there was practically no difference between the ratings awarded by respondents who were willing (W) and by respondents who were indifferent $(\mathrm{X})(\mathrm{W}-1.62 \pm 3.90 ; \mathrm{X}-1.63 \pm$ 3.46). A similar trend was found among respondents from each of the university faculties. This indicates that the interaction between the variables willingness and education was inconclusive (Table 1). On the other hand, the interaction between the variables willingness and attitude was shown to be conclusive. Within the group of respondents with a positive attitude toward wind energy, those willing to live near WTs (category W within willingness) awarded the highest ratings. The average ratings among respondents with a neutral or 


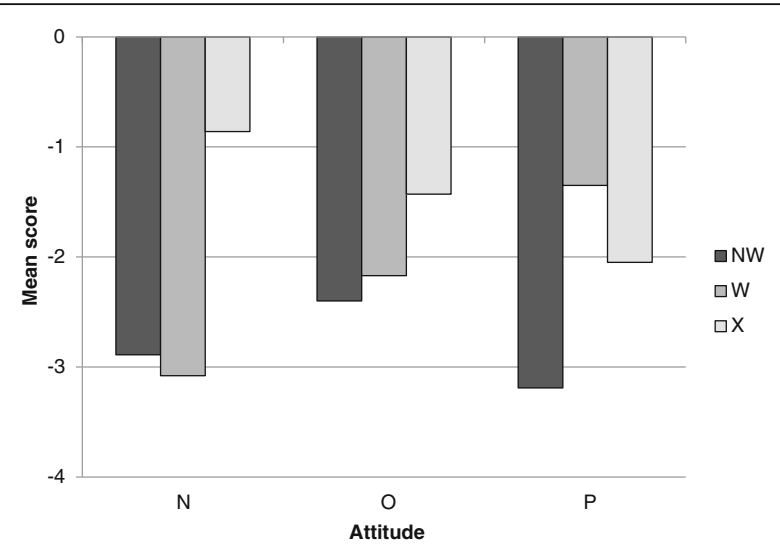

Fig. 2 Mean score of landscape evaluations according to the respondent's willingness to live near wind turbines ( $W$ willing, $N W$ not willing, $X$ no opinion) and according to general attitude toward wind energy ( $N$ negative, $O$ neutral, $P$ positive)

negative attitude did not differ markedly in this respect (i.e. the ratings awarded by those unwilling to live near WTs and the ratings awarded by those willing to live near WTs were similar) (Fig. 2).

\section{Presence of WTs within $10 \mathrm{~km}$ of the respondent's home} Respondents living near WTs (within $10 \mathrm{~km}$ ) evaluated landscapes with WTs more positively (mean \pm SD $-1.65 \pm 3.65)$ than did respondents with no WTs in the vicinity of their place of residence (mean \pm SD $-2.20 \pm 3.50$, Table 1). Furthermore, the interaction between the variables presence of WTs within $10 \mathrm{~km}$ of respondent's home (presence) and general attitude toward wind energy (attitude) proved significant. While the average ratings among respondents with a neutral attitude $(\mathrm{O})$ were not influenced by the presence of WTs near their place of residence (the average ratings of the two groups differed only slightly), the average ratings awarded by respondents with clear

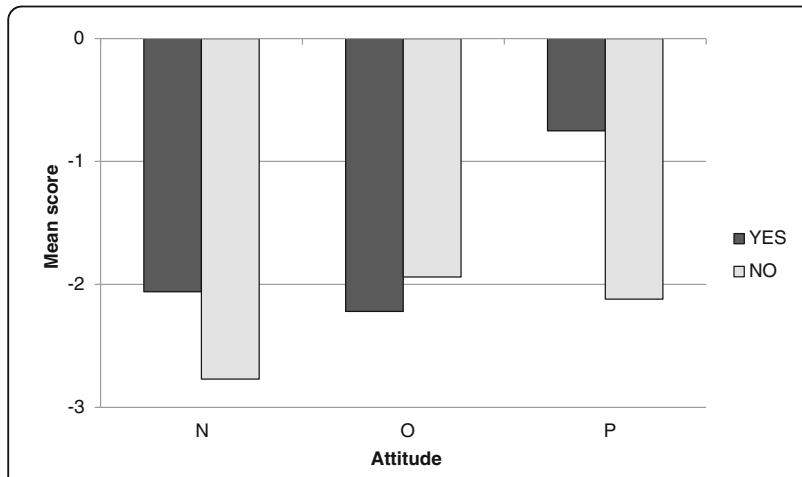

Fig. 3 Mean score of landscape evaluations according to the presence of wind turbines within $10 \mathrm{~km}$ of the respondent's home (yes $\times$ no) and according to the respondent's general attitude toward wind energy ( $N$ negative, $O$ neutral, $P$ positive) attitudes (negative or positive) were always higher for respondents living near WTs than for those respondents not living near WTs (Fig. 3).

\section{General attitude toward wind energy}

Respondents' ratings of WTs were markedly influenced by their attitude toward wind energy. Not surprisingly, those respondents with a negative attitude toward wind energy awarded the lowest ratings for WTs (mean $\pm \mathrm{SD}-2.67 \pm 3.27$ ), while respondents with a neutral attitude and respondents with a positive attitude awarded very similar ratings $(-1.96 \pm 3.25$ versus $-1.62 \pm 4.06$, respectively). Respondents' attitudes toward wind energy were also evident in all assessed interactions (see explanations above).

\section{Discussion}

The results of the study are focused on four main characteristics of the respondents: their general attitude toward wind energy, their willingness to live near a wind power plant, the presence of WTs near their place of residence, and the orientation of their university studies. In the past 20 years, the authors of this study have processed assessments of more than 1500 WTs for the purposes of sanctioning their installation (more than 180 individual construction projects in the Czech Republic, Germany, and USA). On the basis of practical experience, the discussion here is divided into three subsections according to the three types of authorities involved in the approval process (also taking into consideration the importance of educational orientation): (i) authorities who plan WTs, (ii) authorities who represent the affected public, and (iii) those who make decisions as public administration authorities.

\section{Importance of educational orientation for planners}

What kind of education is most relevant for planners dealing with wind farms? This is a question that has until now not been discussed in detail in the literature. Our study is the first to provide results based on respondents' differing perceptions of WTs according to the orientation of their studies (i.e. their professional orientation). The results obtained by comparing attitudes of respondents from universities with different orientations (in this case, environmental studies versus technical studies) reveal a distinct difference in how WTs are perceived within a landscape. Students with a technical orientation award a markedly higher rating to WTs in the landscape than do students studying environmental sciences. Furthermore, it was determined that, among technical students, a respondent's general attitude toward wind energy (positive, neutral, negative) does not influence his/her ratings of landscapes with WTs, whereas it markedly influences the ratings awarded by students of 
environmental sciences. However, students with a positive attitude toward wind energy awarded higher ratings to landscapes with WTs.

The lack of significant influence of general attitude toward wind energy on the perception of landscapes with WTs among respondents with a technical background implies that they perceive wind power plants only as technical structures designed for a certain use [35]. Respondents with an environmental orientation, on the other hand, perceive WTs not only as structures but above all as components of the landscape. A similar divergence in the perception of WTs was demonstrated in a study on a planned wind park in the Wadden Sea [28]. It is apparent that assessments of the suitability of a landscape for the placement of WTs are not to be ignored and should form an integral part of the decisionmaking process $[25,27]$.

This begs the question: Who, in that case, should plan the construction of wind parks and propose where WTs should be placed in the landscape, while taking into the account the landscape type and its natural, aesthetic, and historic values? Technically educated planners are likely to give greater consideration to construction technologies and to functionality than to landscape values. This entails a risk that these functionally based proposals will be opposed and overturned during the subsequent environmental assessment process. Insensitive placement within the landscape may not be identified until the landscape impact assessment. This will result in time delays and financial losses for the investor and potentially also for the planner. Alternatively, insensitively placed WTs may be approved, leading to negative impacts on landscape values. At the same time, it should be recognized that some results among groups of environmentally oriented students point to an excessively conservative, uncompromising commitment to landscape preservation and protection. Our results have adumbrated these tendencies primarily among those environmentally educated respondents with negative attitudes toward wind energy.

While education in a certain field leads to increasing knowledge in the field of specialization, this can be accompanied by neglect for and ignorance of knowledge from other fields of study. Specialists in environmental fields, for example, incline toward protecting the landscape and its values, rather than toward developing new technologies, such as the construction and development of renewable energy sources (including wind parks). Specialists in technical fields, on the other hand, are more focused on the development and implementation of technology, and they often disregard or underrate landscape values. This statement may seem ideologically based, but the results of our study and many others $[28,29,31,35]$ have demonstrated considerable differences in landscape perceptions between respondents from technical fields and respondents from environmental fields. Such perceptions and opinions may be shaped by the personality of each individual, even before he or she registers as a student. Personal ideas, attitudes, and objectives are an important factor in the choice of a study programme, and these initial opinions are likely to be further shaped and entrenched in the course of the study programme.

The perception of WTs may be influenced by a lack of knowledge about the subject or by unwillingness to accept other values and opinions. Whatever influences there are on individual students, a melding of technical and environmental knowledge among experts from different fields can be achieved only in part. One way to deal with this issue, which is not trivial, would be to provide special interdisciplinary courses in this subject area. These courses may provide technical knowledge to environmentalists and expand the knowledge of environmental issues among engineers and planners. By acquiring basic knowledge and an appreciation for the landscape values which are at risk of being disturbed by the construction of WTs, planners will be better able to judge at the very outset of planning whether a proposal will or will not be successful. At the same time, environmentalists can learn more about technological (and economic) considerations.

\section{Public opposition to/acceptance of wind parks}

This subsection expands on the results of WT perception ratings from the perspective of the distance of proposed WT structures from the place of residence of respondents who may be affected by them. The discussion also indicates which respondents should be included in the planning and approval process on the basis of their proximity to proposed WTs.

As expected, respondents not willing to live near WTs awarded lower ratings to landscapes with WTs than respondents who are willing to live near WTs or who expressed a neutral opinion. Surprising results were obtained, however, for the interaction between the factors willingness to live near WTs and general attitude toward wind energy. It had been expected that respondents with a negative general attitude to wind energy would award low ratings to landscapes with WTs, regardless of their willingness to live near WTs. Surprisingly, the highest ratings came from respondents with a negative attitude, but who expressed indifference about living near WTs. Respondents with a positive attitude toward wind energy and also willingness to live near WTs awarded much lower ratings. Nevertheless, an expected trend was found in the ratings awarded by respondents willing to live near WTs. Their ratings correlate positively with their attitudes toward wind energy. By contrast, those unwilling to live near WTs unexpectedly awarded the lowest 
rating in combination with a positive attitude toward wind energy. We had anticipated that they would award the worst ratings in combination with a negative attitude. A positive attitude toward wind energy was apparently entirely eclipsed by the unacceptability of living near WTs. Even though they were proponents of wind energy, they would not accept living near WTs. This result is an example of the NIMBY effect, which has become the topic of a number of studies, though none of them has clearly confirmed that the NIMBY effect in fact exists [e.g. 9, 10]. The ratings awarded by respondents with a neutral attitude to the possibility of living near WTs have an inverse character. The highest ratings are awarded by respondents with a negative general attitude to wind energy, while respondents with a positive general attitude to wind energy awarded the lowest ratings.

Interesting results were registered for the interaction between the factors general attitude toward wind energy and presence of WTs within $10 \mathrm{~km}$ of respondent's home. Those with a negative attitude to wind energy and who did not live near WTs awarded the lowest ratings, while respondents with a positive attitude and living near WTs awarded the highest ratings. This supports the hypothesis that people can to a certain degree become accustomed to WTs. This finding has also been demonstrated by other studies $[6,13]$.

\section{Who should be included in the planning and decision- making process?}

A general clear-cut attitude (positive or negative) toward wind energy has an important influence on the perception of new wind farm projects. It can be assumed that people with a negative attitude will tend to remain rather negative, even after WTs have been constructed, as demonstrated in this study and also by Read et al. [32]. Read et al. found that a negative attitude toward wind farms tends to be based on a past attitude, and that the tendency to oppose wind farm developments is strongly associated with past oppositional behaviour (i.e. past behaviour is the best predictor of future behaviour in this matter). Choice experiment methods [36] have proven effective in planning WTs. In this method, respondents are asked which location out of a number of options they consider most suitable. Ek and Persson [36] demonstrated, for example, the importance of three main considerations: avoidance of recreation areas, co-ownership of WTs by the community, and community involvement in the decision-making process. Many other studies have concluded that it is crucial to involve the local population in the process $[5,10,18,24]$. An important question is therefore: What group of respondents should be included in the assessment process? The authors' own experience, also supported by results, shows that there are three such groups. The first group consists of inhabitants living in the immediate vicinity of the proposed location (i.e. within $1.5 \mathrm{~km}$ ) and who are thus directly affected acoustically and visually by the WTs. The second group should include inhabitants of indirectly affected areas between ca 1.5 and $10 \mathrm{~km}$ distant. This group is affected only by the visual impacts of WTs [25, 32]. According to several studies, place attachment has considerable influence on perception [17-19]. The third group should comprise respondents generated from vacationers and other occasional visitors to the area. While Frantal and Kunc [37] found no significant influence of WT construction on the number of visitors to recreation areas in the Czech Republic, other studies have highlighted marked opposition and disagreement among the general public concerning popular recreation areas $[8,10]$.

\section{Educational orientation of sanctioning bodies}

In this subsection, we come to a classic scenario when a wind park is sanctioned. A wind park with a certain number of WTs is proposed in a specific location. There are objections from environmentalists, the public, and the local inhabitants. The proposal is awaiting assessment by a competent public administration authority as to whether the project will be sanctioned and, if so, under what conditions. This presents the situation in a very simplified way, but it leads essentially to a single question: What professional knowledge should the responsible employee of the planning and sanctioning public administration authority have in order to ensure that the proposal is assessed adequately and impartially?

More than $85 \%$ of wind farm proposals are rejected in the Czech Republic. This suggests that the planning and sanctioning bodies have no clear objective or methodology for approaching the construction of WTs. The results of our study have indicated that students in technical study programmes and students in environmental study programmes form very different camps as regards their perceptions of WTs. This can have a crucial influence on the processes of planning, evaluation, and final approval. It can be inferred that the planning and sanctioning authorities and their representatives should not be inclined to only one camp. The members of these bodies therefore need to have both environmental knowledge (i.e. about impacts on the landscape and its values, noise, etc.) and technical knowledge. An impartial assessment is best achieved by a neutral general attitude toward wind energy. The results of this study show that respondents with a neutral general attitude award very similar ratings, whether or not there are WTs near their homes. Other studies have also demonstrated the influence of general attitude on the perception of specific projects [27, 38]. 
A large proportion of projects are rejected on the basis of non-acceptance by the public, rather than on the basis of an adequate assessment by the planning and sanctioning bodies $[6,28]$. Although environmental impact assessments have been provided by independent experts, proposed projects are often stopped in response to strong opposition by the public. It would therefore be only a modest overstatement to say that a proposal that will have a great impact on the landscape and its values can be approved as long as there is no considerable public opposition. To put it another way, as long as there is no major public opposition to a proposal, no other considerations will make it unacceptable. In practice, this points to an ineffectively functioning system.

The fact is that developers often do not discuss their proposals with the public or with local communities. Instead, they take the course of "stealthy" construction, hoping that no large wave of protests against the proposal will arise. As has already been mentioned, this approach is ineffective in practice and leads to delays in the project or to its outright cancellation [2-6]. The sanctioning body should play the role of mediator, directing the entire process and thereby facilitating communication between the main stakeholder parties-the developers and the affected inhabitants. Members of the sanctioning body should also know the location in question very well, including the landscape and its values, in order to make an adequate assessment of possible negative impacts.

If a developer proposes the construction of a new wind farm, the sanctioning body should lead the entire process. Locations where the impact would be smallest can be identified on the basis of an expert landscape analysis. A similar process is mentioned, for example, in a study from the UK that assesses several locations from the perspective of suitability for construction [39]. Although the topic is different, a study on finding a suitable location for a landfill site presents a similar case [40]. Out of 20 technically suitable locations, only 5 were selected as socially acceptable. The procedures of the sanctioning body can be summarized in three basic steps. First, the sanctioning body should inform the developers and planners about the possible locations and landscape values and should indicate suitable locations. During this process, it should inform the local communities about the planned project and should monitor communication with the developers. Finally, it should make an adequate assessment of the proposed project and should suggest design modifications, in the event that only part of the project can be sanctioned. Thus, at the very start of the process, there is a procedure for steering clear of unsuitable locations and thereby preventing the loss of time and money. Communication with the concerned inhabitants and with the public should be stipulated by the sanctioning body in such a way that developers are not able to avoid participating or participation should be required by law. This planning and decision-making process should be directed by an impartial person, by someone with a neutral attitude toward WTs. If this director has a markedly positive or negative attitude, there is a risk that his or her attitude will influence the authority's decision.

\section{Conclusions}

This study has contributed new knowledge about respondents' perception of WTs within the landscape on the basis of four respondent characteristics: general attitude toward wind energy, educational background, presence of WTs near the respondent's home, and willingness to live near WTs. All four monitored characteristics were evaluated as being very significant for the overall rating. Our study has also analysed the practical application of the results on the basis of distinguishing three main groups involved in the planning process: planners, the affected public, and sanctioning bodies. It also proposes how the results may be applied.

Our study is the first to have demonstrated the importance of respondents' educational orientation. It has shown clearly that students with a technical education are likely to perceive WTs rather as functional structures, while students with an environmental education are likely to give greater weight to the impact of WTs on the landscape and its values. Professional knowledge therefore distinctly influences perception. Thus, environmental knowledge and environmental protection have an important place in evaluating WTs within a landscape. These topics are not studied in depth in engineering study programmes, and technical students therefore normally do not perceive the need for landscape protection so strongly. Professional knowledge about environmental matters is very important for planners, and it should also be considered relevant for representatives of the sanctioning authorities. One way to raise awareness and knowledge of environmental issues would be to provide interdisciplinary coursework dealing with this topic.

Our study has also confirmed the hypothesis that people can to a certain degree get accustomed to WTs. However, this was demonstrable only among respondents with a positive attitude toward wind energy generally. There is a less marked tendency for respondents with a negative attitude toward wind energy to get accustomed to the presence of WTs, and the situation is entirely unclear in the case of respondents with a neutral attitude. The general attitude toward wind energy therefore plays a very 
important role in the perception of WTs, even after WTs have been constructed in the vicinity of a respondent's home. On the basis of experience and accumulated findings, the authors have designated three main groups of concerned people who may be affected by the construction of WTs and who should therefore be included in the planning process. These are inhabitants living in the immediate vicinity (i.e. within $1.5 \mathrm{~km}$ ), who are affected visually and acoustically; inhabitants living within $10 \mathrm{~km}$ and who are thus affected visually; and people who are vacationers and/or occasional visitors to the area. A neutral attitude toward wind energy is a desirable basic characteristic for sanctioning bodies and relevant authorities, as neutrality is necessary for an adequate and impartial assessment of proposals.

Willingness to live near WTs also has a significant influence on the perception of WTs in the landscape, especially among the affected public. Although wind energy is generally viewed positively by respondents, most of them nevertheless evaluate specific projects negatively. Among the affected respondents, therefore, it is not so much how they perceive wind energy that is important-what really matters is their willingness to adjust. Open presentation of a proposed project by the developers, communication with the local communities, and including them in the decision process are very important for the successful development of the entire project.

Finally, this study has indicated the importance of adequate education for planning wind parks. Sanctioning bodies should be able adequately and impartially to evaluate each proposed project, to assess the level of impact on the landscape and its values, including aesthetic values and on the population, as well as other impacts caused by the structures and the activities of WTs. Likewise, it is important for the public and the local communities to be aware of these issues. Awareness can ensure that there is only sensible opposition to projects, and that developers have no justification for claiming that opposition merely reflects NIMBYism. Planners need to be well educated in the area of environmental protection. This will enable them from the very outset to prevent developers proceeding with proposals that would have an unnecessarily large impact on the landscape. Project proposals that would lead to loss of money and wasted time, and other unfavourable outcomes, need to be dropped as early as possible in the proceedings. Communication between developers and local communities, mediated by the sanctioning bodies, is crucial for creating transparency and more efficient planning of wind park construction.

\section{Acknowledgements}

This study was supported by Grants No. 20134279 and No. 20144220 from the Internal Grant Agency of the Faculty of Environmental Sciences at Czech
University of Life Sciences in Prague, Czech Republic, and by Grant No. LH11069 from the Ministry of Education, Youth and Sports of the Czech Republic.

\section{Authors' contributions}

The manuscript was designed and prepared by all authors. All authors read and approved the final manuscript.

\section{Authors' information}

VB is at the PhD position at the Faculty of Environmental Sciences (FES) at Czech University of Life Sciences (CULS) in Prague. She is also practising architect and designer. Her focus study is visual preferences for wind turbines. She has done studies on landscape character, including cultural and natural attributes of landscapes and their evaluation in local and regional (national) context. JV is postdoctoral scholar at FES in Prague and Head of the Department of Ecology. His research is focused on communities and populations of amphibians. Special attention of his research is paid to the pollution areas, landscapes that have undergone mineral resources mining, protected and otherwise valuable territories. He is involved in statistical data analysis of other research at FES. PS is a professor of Applied and Landscape Ecology at FES in Prague, Vice-Dean for Science and Research and Head of the Department of Land Use and Improvement. His work includes research, teaching, projecting, and service in landscape planning. Particularly, he focuses on landscape ecology (landscape pattern changes and edge effect), visual resources management, and land-use planning questions and issues.

\section{Competing interests}

The authors declare that they have no competing interests.

Received: 29 April 2016 Accepted: 13 October 2016

Published online: 07 November 2016

\section{References}

1. Kaldellis JK, Zafirakis D (2011) The wind energy (r)evolution: a short review of a long history. Renew Energy 36(7):1887-1901. doi:10.1016/j.enpol.2010.01.051

2. Jones CR, Eiser JR (2010) Understanding 'local' opposition to wind development in the UK: how big is a backyard? Energy Policy 38(6): 3106-3117. doi:10.1016/j.enpol.2010.01.051

3. Ladenburg J (2009) Visual impact assessment of offshore wind farms and prior experience. Appl Energy 86(3):380-387. doi:10.1016/j.apenergy.2008.05.005

4. Meyerhoff J, Ohl C, Hartje V (2010) Landscape externalities from onshore wind power. Energy Policy 38(1):82-92. doi:10.1016/j.jocm.2013.04.010

5. Tsoutsos T, Tsouchlaraki A, Tsiropoulos M, Serpetsidakis M (2009) Visual impact evaluation of a wind park in a Greek island. Appl Energy 86(4): 546-553. doi:10.1016/j.apenergy.2008.08.013

6. Warren CR, Lumsden C, O'Dowd S, Birnie RV (2005) 'Green on green': public perceptions of wind power in Scotland and Ireland. J Environ Plan Manag 48(6):853-875. doi:10.1080/09640560500294376

7. Ek K (2005) Public and private attitudes towards "green" electricity: the case of Swedish wind power. Energy Policy 33(13):1677-1689. doi:10.1016/j. enpol.2004.02.005

8. Ladenburg J (2010) Attitudes towards offshore wind farms - the role of beach visits on attitude and demographic and attitude relations. Energy Policy 38(3):1297-1304. doi:10.1016/i.enpol.2009.11.005

9. Petrova MA (2013) NIMBYism revisited: public acceptance of wind energy in the United States. Wiley Interdiscip Rev Clim Chang 4(6):575-601. doi:10.1002/wcc.250

10. Wolsink M (2007) Planning for renewable schemes: deliberative and fair decision-making on landscape issues instead of reproachful accusations of noncooperation. Energy Policy 35(5):2692-2704. doi:10.1016/j.landusepol. 2009.04.004

11. Wolsink M (2012) Undesired reinforcement of harmful 'self-evident truths' concerning the implementation of wind power. Energy Policy 48:83-87. doi:10.1016/j.enpol.2012.06.010

12. Meyerhoff J (2013) Do turbines in the vicinity of respondents' residences influence choices among programmes for future wind power generation? J Choice Model 7:58-71. doi:10.1016/j.jocm.2013.04.010

13. Eltham DC, Harrison GP, Allen SJ (2008) Change in public attitudes towards a Cornish wind farm: Implications for planning. Energy Policy 36(1):23-33. doi:10.1016/j.enpol.2007.09.010 
14. Groth TM, Vogt C (2014) Residents' perceptions of wind turbines: an analysis of two townships in Michigan. Energy Policy 65:251-260. doi:10.1016/j.enpol. 2013.10.055

15. Swofford J, Slattery M (2010) Public attitudes of wind energy in Texas: local communities in close proximity to wind farms and their effect on decisionmaking. Energy Policy 38(5):2508-2519. doi:10.1016/j.ecoleng.2011.08.007

16. Horst D (2007) NIMBY or not? Exploring the relevance of location and the politics of voiced opinions in renewable energy siting controversies. Energy Policy 35(5):2705-2714. doi:10.1016/j.enpol.2006.12.012

17. Devine-Wright P, Howes $Y$ (2010) Disruption to place attachment and the protection of restorative environments: a wind energy case study. J Environ Psychol 30:271-280. doi:10.1016/j.jenvp.2010.01.008

18. Haggett C (2011) Understanding public responses to offshore wind power Energy Policy 39(2):503-510. doi:10.1016/j.enpol.2010.10.014

19. Hall N, Ashworth P, Devine-Wright P (2013) Social acceptance of wind farms: analysis of four common themes across Australian case studies. Energy Policy 58:200-208. doi:10.1016/j.enpol.2013.03.009

20. Aitken M (2010) Why we still don't understand the social aspects of wind power: a critique of key assumptions within the literature. Energy Policy 38(4):1834-1841. doi:10.1016/j.enpol.2009.11.060

21. Lewicka M (2011) Place attachment: how far have we come in the las 40 years? J Environ Psychol 31(3):207-230. doi:10.1016/j.jenvp.2010.10.001

22. Rollero C, De Piccoli N (2010) Place attachment, identification and environment perception: an empirical study. J Environ Psychol 30(2): 198-205. doi:10.1016/j.jenvp.2009.12.003

23. Soini K, Vaarala H, Pouta E (2012) Residents' sense of place and landscape perceptions at the rural-urban interface. Landsc Urban Plan 104(1):124-134 doi:10.1016/j.landurbplan.2011.10.002

24. Hübner G (2012) Die Akzeptanz von erneuerbaren Energien. Ekhardt, F. et al. Erneuerbare Energien. Ambivalenzen, Governance, Rechtsfragen, pp 117-137

25. Betakova V, Vojar J, Sklenicka P (2015) Wind turbines location: how many and how far? Appl Energy 151:23-31. doi:10.1016/j.apenergy.2015.04.060

26. Lothian A (2008) Scenic perceptions of the visual effects of wind farms on South Australian landscapes. Geogr Res 46(2):196-207. doi:10.1111/j.17455871.2008.00510.x

27. Molnarova K, Sklenicka P, Stiborek P, Svobodova K, Salek M, Brabec E (2012) Visual preferences for wind turbines: location, numbers and respondent characteristics. Appl Energy 92:269-278. doi:10.1016/j.apenergy.2011.11.001

28. Wolsink M (2010) Near-shore wind power-protected seascapes, environmentalists' attitudes, and the technocratic planning perspective. Land Use Policy 27(2):195-203. doi:10.1016/j.landusepol.2009.04.004

29. Svobodova K, Sklenicka P, Molnarova K, Salek M (2012) Visual preferences for physical attributes of mining and post-mining landscapes with respect to the sociodemographic characteristics of respondents. Ecol Eng 43:34-44. doi:10.1016/j.ecoleng.2011.08.007

30. De Feo G, Williams ID (2013) Siting landfills and incinerators in areas of historic unpopularity: surveying the views of the next generation. Waste Manag 33(12):2798-2810. doi:10.1016/j.wasman.2013.08.019

31. Ryan RL (2012) The influence of landscape preference and environmental education on public attitudes toward wildfire management in the Northeast pine barrens (USA). Landsc Urban Plan 107(1):55-68. doi:10.1016/j.landurbplan. 2012.04.010

32. Read DL, Brown RF, Thorsteinsson EB, Morgan M, Price I (2013) The theory of planned behaviour as a model for predicting public opposition to wind farms development. J Environ Psychol 36:70-76. doi:10.1016/j.apenergy. 2011.11.001

33. Team RC (2013) R: A Language and Environment for Statistical Computing. R Foundation for Statistical Computing, Vienna

34. Crawley MJ (eds) (2007) The R Book, John Wiley \& Sons, Chichester, England

35. Tikka PM, Kuitunen MT, Tynys SM (2000) Effects of educational background on students' attitudes, activity levels, and knowledge concerning the environment. J Environ Educ 31(3):12-19. doi:10.1080/00958960009598640

36. Ek K, Persson L (2014) Wind farms - where and how to place them? A choice experiment approach to measure consumer preferences for characteristics of wind farms establishments in Sweden. Ecol Econ 105:193-203. doi:10.1016/j. ecolecon.2014.06.001

37. Frantal B, Kunc J (2010) Wind turbines in tourism landscapes, Czech experience. Ann Tour Res 38(2):499-519. doi:10.1016/j.annals.2010.10.007
38. Walter $\mathrm{G}$ (2014) Determining the local acceptance of wind energy projects in Switzerland: the importance of general attitudes and project characteristics. Energy Res Soc Sci 4:78-88. doi:10.1016/j.erss.2014.09.003

39. Baban SMJ, Parry T (2001) Developing and applying a GIS-assisted approach to locating wind farms in the UK. Renew Energy 24(1):59-71. doi:10.1016/ S0960-1481(00)00169-5

40. Simsek C, Elci A, Gunduz O, Taskin N (2014) An improved landfill site screening procedure under NIMBY syndrome constraints. Landsc Urban Plan 132:1-15. doi:10.1016/j.landurbplan.2014.08.007

\section{Submit your manuscript to a SpringerOpen ${ }^{\circ}$ journal and benefit from:}

- Convenient online submission

- Rigorous peer review

- Immediate publication on acceptance

- Open access: articles freely available online

- High visibility within the field

- Retaining the copyright to your article

Submit your next manuscript at $>$ springeropen.com 